\title{
Student incentives and preferential treatment in college admissions ${ }^{\text {is }}$
}

\author{
Ivan Pastine ${ }^{\mathrm{a}, 1}$, Tuvana Pastine ${ }^{\mathrm{b}, *}$ \\ a University College Dublin, Ireland \\ b National University of Ireland Maynooth, Ireland
}

\section{A R T I C L E I N F O}

\section{Article history:}

Received 25 April 2010

Received in revised form 8 September 2011

Accepted 15 September 2011

\section{JEL classification: \\ HO}

J7

\section{Keywords:}

Affirmative action

College admissions

All-pay auction

Contest

Tournament

\begin{abstract}
A B S T R A C T
We consider a framework in which the optimal admissions policy of a purely academicquality oriented college implements preferential treatment in favor of the student from the deprived socioeconomic background which maximizes the competition between candidates. We find that the exact form of the preferential treatment admissions policy matters for student incentives and hence for student-body diversity in equilibrium. Preferential treatment policy in college admissions often takes, or is perceived to take, an additive form where the score of the applicant from the deprived background is augmented by a fixed number of points. Such a preferential treatment policy fails to incentivize students from the deprived background. Despite the affirmative action, the level of preferential treatment that achieves academic excellence leaves student-body diversity unchanged compared with a background-blind admissions policy and leads to a higher intergroup score gap.
\end{abstract}

(c) 2011 Elsevier Ltd. All rights reserved.
"Whites scoring between 163 and 167 on the LSAT are routinely rejected by the Law School, and thus whites aspiring to admission at the Law School have every incentive to improve their score to levels above that range. [...] Blacks, on the other hand, are nearly guaranteed admission if they score above 155. [...] there is no incentive for the black applicant to continue to prepare for the LSAT once he is reasonably assured of achieving the requisite score."

Dissenting Opinion of Justice Thomas in Grutter v. Bollinger (2003)

\footnotetext{
is We would like to thank John McGinnity for helpful comments.

* Corresponding author. Tel.: +3531 708 6421; fax: +3531 1083934 . E-mail addresses: Ivan.Pastine@ucd.ie (I. Pastine),

Tuvana.Pastine@nuim.ie (T. Pastine).

1 Tel.: +3531 716 8395; fax: +35312830068.
}

\section{Introduction}

In Grutter v. Bollinger (2003), the Supreme Court approved the use of race as a factor in the admissions decisions of the Law School of the University of Michigan. In practice this landmark ruling leaves the door open for a holistic socioeconomic background-sighted admissions policy allowing a less academically qualified candidate to be preferred. Opponents of preferential treatment admissions policies often claim that students subject to preferential treatment have less incentive to put in effort to achieve higher academic quality. Therefore students from different backgrounds are more likely to be polarized in quality which may aggravate statistical discrimination in the post-college job market. In this paper we analyze the effect of college admission policies on effort incentives of students from differing socioeconomic backgrounds.

The theoretical literature on affirmative action in education has grown rapidly since the 1996 California ban on 
color-sighted admissions in public schools. ${ }^{2}$ The strand of the literature most closely related to this paper studies how an academic-quality oriented college may use affirmative action admissions policies to increase the expected quality of the incoming class. ${ }^{3}$ In an all-pay auction framework Fu (2006) finds that affirmative action through preferential treatment creates positive cross-group interaction between applicants. ${ }^{4}$ It helps level the playing field inducing candidates from both privileged and underprivileged backgrounds to invest more heavily in educational attainment. Hence the optimal admissions policy of a purely academic-quality oriented college gives preferential treatment to the applicant from a disadvantaged background. Furthermore the college's objective of academic excellence is in harmony with student-body diversity. The optimal admissions policy of a purely academic-quality oriented college also yields full student-body diversity as a byproduct. 5

In this paper we adapt $\mathrm{Fu}$ (2006) to investigate how the student effort incentive effects and student-body diversity depend on the exact form of the policy. Fu (2006) examines affirmative action policy with a multiplicative form: the "academic achievement score" of a candidate from an underprivileged background is multiplied by a constant greater than one. However, preferential treatment policies often take an additive form. For example, the undergraduate admissions office of the College of Arts and Sciences at the University of Michigan added 20 points (out of 150) to the underprivileged candidate's academic achievement score. ${ }^{6}$ Espenshade, Chung, and Walling (2004) estimates that in three academically selective U.S. universities on average the admissions policies implicitly add 230 extra

\footnotetext{
2 A number of states have banned affirmative action based on race in public colleges either by court order, referendum or Governor's initiative. In addition to California, these include Louisiana (1996), Mississippi (1996), Texas (1996), Washington (1998), Florida (2000) and Georgia (2001). Public opinion is divided on the question of affirmative action with opponents gaining momentum. Affirmative action policy was a ballot measure in two states in the 2008 U.S. elections. While Colorado voted for affirmative action (51\%), Nebraska voted against it (58\%).

3 Another important strand of the literature considers colleges that have diversity as one of their goals. In these frameworks a ban on color-sighted admissions policies can lead the college to use less efficient means to achieve diversity. Examples of this literature include Chan and Eyster (2003), Fryer and Loury (2005a, 2005b), Fryer, Loury, and Yuret (2007) and Epple, Romano, and Sieg (2008). Hickman (2010) has a sophisticated alternative approach, looking at the global effect of an arbitrary affirmative action policy without consideration of an individual college's goals or incentives.

${ }^{4}$ Franke (2010) shows that the results in Fu (2006) also hold in a framework with a stochastic success function.

5 Furstenberg (2007) considers a college that uses test scores to infer students' innate ability. Students with the same innate ability but from different socioeconomic backgrounds differ in their cost of improving their test scores. Therefore an academic-quality oriented school has differing test score cutoffs for white and black students. Nevertheless the qualitative results are similar to $\mathrm{Fu}$ (2006). Affirmative action is used to increase the quality of the student body which has the byproduct of increased student-body diversity compared to a background-blind admissions policy.

6 The Supreme Court ruled out this rigid scoring practice in Gratz v. Bollinger (2003). Whether a background sighted admissions policy is officially announced as a rigid scoring rule or simply perceived by students as an additional bonus makes no difference for the purposes of this paper.
}

SAT points (on a 1600 scale) to the scores of African American students. In the most selective 20 percent of four-year U.S. institutions, Kane (1998) finds that being black or Hispanic gives an advantage of approximately 400 SAT points. ${ }^{7}$ Since affirmative action policies often add or are perceived to add extra points, we depart from Fu (2006) by analyzing an additive form of the preferential treatment admissions policy.

We find that a purely academic-quality oriented college implements moderate preferential treatment in favor of the applicant from a deprived socioeconomic background. However, the additive preferential treatment that maximizes expected academic quality leaves the expected academic achievement of the student from the deprived background unaltered while the student from the privileged background puts in more effort to overcome the handicap. In equilibrium, this simply leads to a higher score gap between students from different backgrounds without altering student-body diversity compared with a background-blind admissions policy.

The differences in the incentive structures of the two preferential treatment rules lead to the differences in the implications of the models. A multiplicative preferential treatment policy increases the marginal benefit of effort for the student from a disadvantaged background. This induces greater academic effort on his part and in equilibrium results in a higher probability of admission. On the other hand, an additive affirmative action policy does not alter the marginal benefit of effort for a underprivileged candidate. The bonus points are added irrespective of the performance of the student and so do not incentivize the student to put in additional effort, as intuitively suggested by Justice Thomas. Therefore the exact implementation of the preferential treatment policy, whether multiplicative or additive, can dramatically alter its effects on student incentives and equilibrium student-body diversity.

Section 2 presents the model and the equilibrium admissions policy. Section 3 discusses student-body diversity and the intergroup score gap in equilibrium. Section 4 concludes with a summary of the results.

\section{The model}

There are two risk-neutral candidates who compete for a single seat at a college: a candidate from a privileged socioeconomic background and a candidate from a deprived socioeconomic background denoted by $P$ and $D$, respectively. The timing of the college admissions game is as follows: the college announces an admissions rule which is based on the test scores and backgrounds of the applicants. Candidates then observe the admissions rule and decide on how much academic effort to put in to prepare for the test.

\footnotetext{
7 While our discussion and much of the empirical literature focuses on the case of the U.S., the existence of socioeconomic tiers is not unique to the U.S. For instance, in an effort to foster social mobility the National University of Ireland Maynooth adds 50 points (on a 600 point scale) to the admissions score of students from disadvantaged socioeconomic backgrounds. NUIM is one of the eight Higher Education Institutions in Ireland that participates in the Higher Education Access Route Program (HEAR). See http://access.nuim.ie/scope/hear.
} 
Their efforts translate into test scores $q_{P}$ and $q_{D}$. The college observes the test scores and the socioeconomic background of the applicants and admits one of them following the previously announced admissions rule.

\subsection{The applicants}

Each applicant has a valuation of a place in college denoted by $V_{i} \in(0, \infty) \forall i \in\{P, D\}$. Applicant $i$ 's effective academic effort $e_{i}$ results in a test score $q_{i}$ via a non-stochastic symmetric linear technology $q_{i}=e_{i}$ and the unit cost of effective effort is $c_{i}$. The payoff to applicant $i$ is $V_{i}-c_{i} e_{i}$ if he is accepted and $-c_{i} e_{i}$ if he is rejected. The valueto-cost ratio is asymmetric where $V_{P} / c_{P}>V_{D} / c_{D}$. There are many potential sources for this asymmetry. For instance students from a deprived background may lack access to effective tutorials for the SAT leading to $c_{D}>c_{P}$. ${ }^{8}$ There may also be inequality in post-college job market opportunities. Students from a deprived socioeconomic background often have less promising job prospects due to factors including statistical discrimination, lack of social networks and/or lack of mainstream business community approved mannerisms, as well as overt discrimination. Poorer postcollege job prospects can result in a lower valuation of the place in college for the student from a deprived background, $V_{D}<V_{P}{ }^{9}$ An applicant from a deprived background may find the monetary cost of attending a selective university more onerous, so the value of admission would be lower for such a candidate, $V_{D}<V_{P}$.

\subsection{The college}

A purely academic-quality oriented college chooses its admissions rule in order to maximize the expected academic quality of the admitted student, which is represented by the expected test score of the incoming student. ${ }^{10}$ The college can base its admissions policy on test scores as well as the socioeconomic backgrounds of the applicants.

We examine admission policies where the college adds a fixed number of points $\gamma \in(-\infty,+\infty)$ to the score of the applicant from the deprived background. The college admits Candidate $D$ if $q_{D}+\gamma>q_{P}$, it admits Candidate $P$ if $q_{D}+\gamma<q_{P}$, and randomly assigns the seat in case of equality. If $\gamma=0$, the college implements a background-blind

\footnotetext{
8 Austen-Smith and Fryer (2005) argues that among minorities aspiring to achieve may be labeled as "acting white" and may be a cause of rejection from the social peer group. This would also result in a higher cost of effort for students from the deprived background.

9 Weinberger and Joy (2007) documents the U.S. racial wage gap among college graduates from 1980 to 2001. Black men in their 20s and 30s earned about 15 percent less than white men, while black women earned about 25 percent less than white men. After controlling for differences in family background, work experience and the type and quality of college education, black men in the same age group earned 8 percent less and black women earned 15 percent less than white men.

10 Rotthoff (2008) points out that the college may have the objective of producing graduates that are highly employable rather than targeting academic quality. Bowen and Bok (1998) suggests that universities may have a broad educational attainment objective that includes creating an environment that fosters social integration. In this paper, however, we assume that the college cares solely about academic excellence.
}

admissions policy. ${ }^{11}$ It is possible to present the results more concisely if we define $f$ as the applicant who is favored by the admissions policy and $u$ as the applicant who is unfavored by the policy. If $\gamma>0$, the admissions policy favors students from a deprived background, $f=D$ and $u=P$. If $\gamma<0$, the college favors the student from the privileged background $f=P$ and $u=D$, a policy that is frequently implemented by giving priority to relatives of alumni. ${ }^{12}$

\subsection{The applicants' equilibrium strategies}

Since the cost of academic effort is sunk irrespective of the identity of the admitted student, the resulting competition between the candidates for the seat in the college takes the form of an all-pay auction where the "bids" of the candidates are their test scores. Hence the model is an adaptation of the all-pay auction of Konrad (2002) to allow for asymmetric valuations of the prize and cost of effort.

If preferential treatment is very strong, $\gamma \geq V_{P} / c_{P}$ or $\gamma \leq-V_{D} / c_{D}$, the unique equilibrium is in pure strategies where candidates put in zero academic effort. Note that $V_{i} / c_{i}$ is the maximum academic effort at which student $i$ 's valuation from admission to the college is non-negative. Hence no candidate would exert academic effort higher than $V_{i} / c_{i}$. If the college implements $\gamma \geq V_{P} / c_{P}$, the candidate from the privileged background would never choose effort of $V_{P} / c_{P}$ since even if his rival had zero effort the privileged student would either lose for sure (if $\gamma>V_{P} / c_{P}$ ) or lose with probability $1 / 2$ (if $\gamma=V_{P} / c_{P}$ ). In either case he would have a negative expected payoff and hence would choose effort $e_{P}=0$. Therefore the preferred student can guarantee admission with zero effort. Thus in equilibrium, with such an extreme preferential treatment admissions policy neither candidate exerts any effort. Likewise if $\gamma \leq-V_{D} / c_{D}$, neither candidate exerts any effort and the place goes to the applicant from the privileged background.

However if $\gamma \in\left(-V_{D} / c_{D}, V_{P} / c_{P}\right)$ equilibrium exists only in mixed strategies. For the unfavored applicant, the best response to effort of $e^{\prime}$ by the favored applicant is either to put $|\gamma|$ more effort than his rival or to drop out of the race altogether, so $e_{f}=e^{\prime}$ would not be optimal. In the allpay auction model of Konrad (2002), the bidder with the head-start advantage (the favored student in our framework) always captures the advantageous position in the competition and has a positive expected value from the contest. The bidder without the head-start advantage has an expected value of zero. However when students have different value-to-cost ratios this is not always the case. Depending on the intensity of the preferential treatment it may be either Candidate $f$ or Candidate $u$ who captures the advantageous position. Hence we need to study the equilibrium in two separate cases.

\footnotetext{
11 For instance, Canadian universities implement a background-blind admissions policy where students simply submit their test scores.

12 Espenshade et al. (2004) estimates that at three highly selective private research universities in the United States, during 1980s the preference for legacy candidates was worth 160 points (on a scale of 1600 ). The college may implement preferential treatment in favor of legacy candidates, as well as affirmative action. Li and Weisman (2011) explores some implications of eliminating affirmative action in such environments.
} 
Using standard methods as in Hillman and Riley (1989) and Baye, Kovenock, and de Vries (1996), the Lemma below characterizes the mixed-strategy equilibrium for $\gamma \in\left(-V_{D} / c_{D}, V_{P} / c_{P}\right)$ where $F_{f}\left(e_{f}\right)$ and $F_{u}\left(e_{u}\right)$ denote the unique equilibrium cumulative distribution functions for academic effort of Candidate $f$ and Candidate $u$, respectively.

\section{Lemma.}

(i) If the admissions policy favors the applicant from the privileged background or if the policy "strongly favors" the applicant from the deprived background, $\gamma \in\left(-V_{D} / c_{D}, 0\right)$ or $\gamma \in\left(V_{P} / c_{P}-V_{D} / c_{D}, V_{p} / c_{p}\right)$, the equilibrium is in mixed strategies only and it is characterized by unique cumulative density functions for the students' effort which are given by:

$$
\begin{gathered}
F_{f}(e)= \begin{cases}\frac{c_{u}}{V_{u}}(e+|\gamma|) & \forall e \in\left[0, \frac{V_{u}}{c_{u}}-|\gamma|\right] \\
1 & \forall e>\frac{V_{u}}{c_{u}}-|\gamma|\end{cases} \\
F_{u}(e)= \begin{cases}\frac{V_{f}-c_{f} V_{u} / c_{u}+c_{f}|\gamma|}{V_{f}} & \forall e \in[0,|\gamma|] \\
\frac{V_{f}-c_{f} V_{u} / c_{u}+c_{f} e}{V_{f}} & \forall e \in\left(|\gamma|, \frac{V_{u}}{c_{u}}\right] \\
1 & \forall e>\frac{V_{u}}{c_{u}}\end{cases}
\end{gathered}
$$

(ii) If the admissions policy "mildly favors" the applicant from the deprived background. $\gamma \in\left[0, V_{P} / c_{P}-V_{D} / c_{D}\right]$, the equilibrium is in mixed strategies only and it is characterized by unique cumulative density functions for the students' effort which are given by:

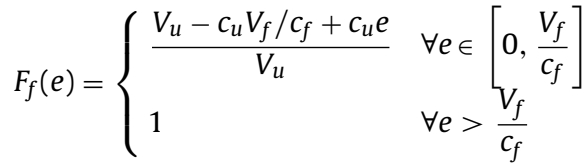

$$
\begin{aligned}
& F_{u}(e)= \begin{cases}0 & \forall e \in[0,|\gamma|] \\
\frac{c_{f}}{V_{f}}(e-|\gamma|) & \forall e \in\left(|\gamma|, \frac{V_{f}}{c_{f}}+|\gamma|\right] \\
1 & \forall e>\frac{V_{f}}{c_{f}}+|\gamma|\end{cases}
\end{aligned}
$$

The proof is in the Appendix A.

In the Lemma part (i), the favored applicant captures the advantageous position. Either the favored applicant comes from a privileged background and enjoys a higher value-to-cost ratio or the favored applicant comes from a deprived background but the degree of preferential treatment is so strong that it overwhelms the value-to-cost ratio advantage of his competitor. In either case, in equilibrium Candidate $f$ can ensure admission if he exerts effort equal to $e_{f}=\left(V_{u} / c_{u}-|\gamma|\right)^{+}$since Candidate $u$ never exerts more effort than $V_{u} / c_{u}$. This allows Candidate $f$ to enjoy a positive expected payoff from the competition equal to $V_{f}-\left(V_{u} / c_{u}\right) c_{f}+c_{f}|\gamma|>0$ and drives down the expected value of Candidate $u$ to zero.

In the Lemma part (ii), the unfavored candidate captures the advantageous position. The admissions policy "mildly favors" the deprived candidate, but the degree of preferential treatment is not strong enough to overcome the valueto-cost ratio advantage of the candidate from the privileged background. In equilibrium while the deprived candidate who is subject to mild affirmative action never exerts more academic effort than $V_{f} / c_{f}$, the candidate from the privileged background does not need to put effort greater than $V_{f} / c_{f}+|\gamma|$ to guarantee admissions. Candidate $u$ captures a positive expected payoff of $V_{u}-\left(V_{f} / c_{f}\right) c_{u}-c_{u}|\gamma|>0$ and the expected payoff of Candidate $f$ is driven to zero.

Candidate $u$ never puts positive probability on exerting effort in the range $(0,|\gamma|]$ since in order to be admitted $u$ needs to exceed $f$ s score at least by $|\gamma|$. Note that in case (i) of the Lemma, there is a positive probability that Candidate $u$ simply chooses not to put in any effort (the probability mass at zero) due to his dim prospects. This probability is increasing in the degree of preferential treatment. The probability that the favored applicant faces a very weak competitor allows Candidate $f$ to relax and so he also has a probability mass at zero effort. However due to preferential treatment $f$ has a positive chance of acceptance even when he puts in no effort. This is not true for the unfavored candidate. In case (ii) of the Lemma $f$ is the candidate with dim prospects. He comes from a deprived background and the affirmative action is not strong enough to turn the tables. There is a positive probability that he may exert no academic effort for his admissions test. But the candidate from the privileged background does not relax. With probability 1 , he puts in positive effort in order to overcome the preferential treatment.

\subsection{The equilibrium admissions policy}

In the first stage of the game the college chooses its optimal admissions rule to maximize the academic achievement of the incoming class. Note that there is strategic interaction between the college and the candidates. The admissions policy affects the students' incentives to put in effort and the college takes this into account via backward induction when announcing its admissions policy..$^{13}$ The college never implements a preferential treatment rule that is so strong that it results in neither student putting in any effort, $\gamma \geq V_{P} / c_{P}$ or $\gamma \leq-V_{D} / c_{D}$. Below we consider the admissions policies that result in competition between the applicants, $\gamma \in\left(-V_{D} / c_{D}, V_{P} / c_{P}\right)$

Since the Lemma implies that ties where $q_{D}+|\gamma|=q_{P}$ occur with zero probability, the expected academic quality of the admitted student $(Q)$ is given by:

$Q=\int_{u} x f_{u}(x) F_{f}(x-|\gamma|) d x+\int_{f} x f_{f}(x) F_{u}(x+|\gamma|) d x$

The unfavored student is admitted only if the score of the favored student is at least $|\gamma|$ points less than the score of the unfavored student. The first term gives the expected

\footnotetext{
13 Empirical work by Long (2004), Dickson (2006), Andrews, Ranchhod, and Sathy (2010) and Furstenberg (2010) using the changes in policy in California, Texas and Florida, show that a college's choice of affirmative action does affect its applicant pool. Cortes (2010) shows that it can also affect student retention and graduation rates.
} 
score of Candidate $u$ if admitted. The second term gives the expected score of the Candidate $f$ if admitted.

If $\gamma \in\left[0, V_{P} / c_{P}-V_{D} / c_{D}\right]$, then from the Lemma,

$$
\begin{aligned}
Q= & \int_{|\gamma|^{+}}^{|\gamma|+V_{f} / c_{f}} x \frac{c_{u} c_{f}}{V_{u} V_{f}}\left(\frac{V_{u}}{c_{u}}-\frac{V_{f}}{c_{f}}+x-|\gamma|\right) d x \\
& +\int_{0}^{V_{f} / c_{f}} x^{2} \frac{c_{u} c_{f}}{V_{u} V_{f}} d x
\end{aligned}
$$

and Leibniz's rule yields:

$$
\frac{\partial Q}{\partial|\gamma|}=\frac{c_{u}}{2 V_{u}}\left(2 \frac{V_{u}}{c_{u}}-\frac{V_{f}}{c_{f}}\right)=\frac{c_{A}}{2 V_{A}}\left(2 \frac{V_{P}}{c_{P}}-\frac{V_{D}}{c_{D}}\right)>0
$$

So the academic quality of the admitted student is increasing in $|\gamma|$ in this range.

If $\gamma \in\left(-V_{D} / c_{D}, 0\right)$ or $\gamma \in\left(V_{P} / c_{P}-V_{D} / c_{D}, V_{P} / c_{P}\right)$, then from the Lemma,

$$
\begin{aligned}
Q & =\int_{|\gamma|^{+}}^{V_{u} / c_{u}} x^{2} \frac{c_{f} c_{u}}{V_{f} V_{u}} d x+\int_{0}^{-|\gamma|+V_{u} / c_{u}} x \frac{c_{f} c_{u}}{V_{f} V_{u}} \\
& \times\left(\frac{V_{f}}{c_{f}}-\frac{V_{u}}{c_{u}}+|\gamma|+x\right) d x
\end{aligned}
$$

and Leibniz's rule yields:

$$
\begin{aligned}
\frac{\partial Q}{\partial|\gamma|}= & \frac{c_{u} c_{f}}{V_{u} V_{f}}\left\{-|\gamma|^{2}+\frac{1}{2}\left(\frac{V_{u}}{c_{u}}-|\gamma|\right)\right. \\
& \left.\times\left[\left(\frac{V_{u}}{c_{u}}-\frac{V_{f}}{c_{f}}-|\gamma|\right)-\frac{V_{f}}{c_{f}}\right]\right\}<0
\end{aligned}
$$

To see the sign of (5) note that if $\gamma<0$ then $V_{u} / c_{u}<V_{f} / c_{f}$ and if $\gamma>V_{P} / c_{P}-V_{D} / c_{D}$ then $V_{u} / c_{u}-V_{f} / c_{f}>\gamma$. In these ranges of $\gamma$ the expected academic quality of the admitted student is strictly decreasing in $|\gamma|$. Since the equilibrium distribution functions are continuous in $\gamma$, so is the expected academic quality of the admitted student. Hence the expected academic quality of the admitted student is maximized at the top of the range where the admissions rule mildly prefers the applicant from the deprived background, $\gamma=$ $V_{P} / c_{P}-V_{D} / c_{D} \equiv \hat{\gamma}$. Note that at $\hat{\gamma}$ the playing field is level in the sense that both candidates have the same expected value from the competition equal to zero.

Proposition 1. A purely academic-quality oriented college adopts a background-sighted preferential treatment admissions rule with $\hat{\gamma}=V_{P} / c_{P}-V_{D} / c_{D}$ which uniquely maximizes the expected academic quality of the incoming class.

Rather than implementing a background-blind admissions policy and simply admitting the student with the highest test score, it is optimal for the college to handicap the student from the privileged background. ${ }^{14}$ To grasp the intuition of this proposition consider the incentive effects of the preferential treatment on the two types of applicants. Fig. 1 graphs the expected test scores of the candidates from privileged and deprived socioeconomic backgrounds

14 Che and Gale (2003) and Fain (2009) have results with a similar flavor in the labor market, where the firm handicaps the more efficient worker. In these papers the contest designer's objective is to maximize the total

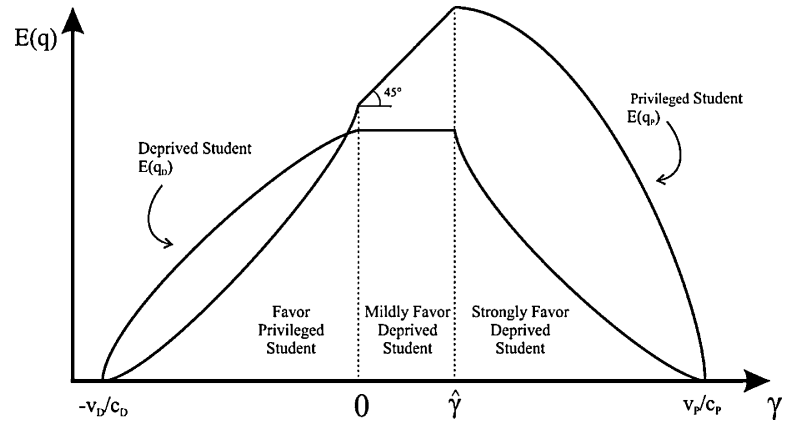

Fig. 1. Expected test scores.

as a function of the preferential treatment parameter for all $\gamma \in\left(-V_{D} / c_{D}, V_{P} / C_{P}\right)$.

If the admissions policy favors the applicant from the privileged background, $f=P$ so $\gamma \in\left(-V_{D} / c_{D}, 0\right)$ or if the policy strongly favors the applicant from the deprived background, $f=D$ and $\gamma \in\left(V_{P} / c_{P}-V_{D} / c_{D}, V_{P} / c_{P}\right)$, the expected academic achievement of the favored applicant is given by:

$$
\int_{0}^{V_{u} / c_{u}-|\gamma|} x f_{f}(x) d x=\int_{0}^{V_{u} / c_{u}-|\gamma|} \frac{x c_{u}}{V_{u}} d x=\frac{c_{u}}{2 V_{u}}\left(\frac{V_{u}}{c_{u}}-|\gamma|\right)^{2}
$$

while the expected academic achievement of the unfavored applicant is given by:

$$
\int_{|\gamma|^{+}}^{V_{u} / c_{u}} x f_{u}(x) d x=\int_{|\gamma|^{+}}^{V_{u} / c_{u}} \frac{c_{f} x}{V_{f}} d x=\frac{c_{f}}{2 V_{f}}\left[\left(\frac{V_{u}}{c_{u}}\right)^{2}-|\gamma|^{2}\right]
$$

Both of these expressions are strictly decreasing in $|\gamma|$. In these ranges of $\gamma$, increasing the preferential treatment tilts the playing field further in favor of Candidate $f$ who already has the advantageous position in the competition. This induces Candidate $u$ to become less aggressive. In return Candidate $f$ also puts less effort. Hence if the college favors the candidate from the privileged background or strongly favors the candidate from the deprived background, the expected academic achievement of students from both backgrounds deteriorates with stronger preferential treatment.

However the situation is different if the admissions policy mildly favors the candidate from the deprived background. Then the expected academic achievement of the applicant from the privileged background is given by:

$$
\int_{|\gamma|^{+}}^{|\gamma|+V_{f} / c_{f}} x f_{u}(x) d x=\int_{|\gamma|^{+}}^{|\gamma|+V_{f} / c_{f}} \frac{c_{f} x}{V_{f}} d x=\frac{V_{f}}{2 c_{f}}+|\gamma|
$$

where $f=D$ and $u=P$. This is increasing in $|\gamma|$ as the candidate from the privileged background has an incentive to put in more effort in order to compensate for the preferential treatment admissions rule.

effort, rather than the quality of the winner (the expected effort of the incoming student in our framework). 
The expected academic achievement of the favored applicant is given by:

$$
\int_{0}^{V_{f} / c_{f}} x f_{f}(x) d x=\int_{0}^{V_{f} / c_{f}} \frac{c_{u} x}{V_{u}} d x=\frac{c_{u}}{2 V_{u}}\left(\frac{V_{f}}{c_{f}}\right)^{2}
$$

Note that this does not depend on $\gamma$. If the admissions rule mildly favors the candidate from the deprived socioeconomic background, his effort distribution is independent of the preferential treatment parameter (see the Lemma, part ii). However, preferential treatment shifts the effort distribution of the privileged candidate to the right by the amount of the bonus added to the other candidate's score. Mild preferential treatment in favor of the applicant from the deprived background induces the privileged student to study more aggressively, yet fails to incentivize the student from the deprived background.

This result is different from Fu (2006) which finds that the expected effort of the student from the deprived background improves when subject to mild multiplicative affirmative action. Multiplicative preferential treatment augments the marginal benefit of effort for the applicant from the deprived background. However, with additive preferential treatment, as is often implemented in practice, the bonus points are added irrespective of the performance of the student. Hence the student from the deprived background does not have an additional incentive to put in effort.

The level of preferential treatment that maximizes the expected academic quality of the incoming class $\hat{\gamma}$ also maximizes the expected effort of the applicant from the privileged background.

However at $\hat{\gamma}$ the expected academic effort of the applicant from the deprived background is the same as under a background-blind admissions policy. Hence the optimal preferential treatment rule is able to provide the highest caliber incoming class due entirely to its positive incentive effect on the candidate from the privileged background.

\section{Student-body diversity and the score gap}

In this section, we evaluate the effects of the optimal admissions rule on student-body diversity and the intergroup test score gap. Student-body diversity is often considered a goal of affirmative action policies. It is argued that diversity itself may have social and educational benefits. For example, an environment where people from diverse backgrounds live and work together may create opportunities for them to get to know one another and to develop understanding and mutual respect. Furthermore balanced representation of people from different backgrounds in higher education may create the sense that upward mobility is possible. These potential benefits are outside of the model. It is nevertheless useful to consider the implications of the equilibrium background-sighted admissions policy on student-body diversity.

Full student-body diversification is achieved when the ratio of admitted students from deprived backgrounds to students from privileged backgrounds is equal to the ratio

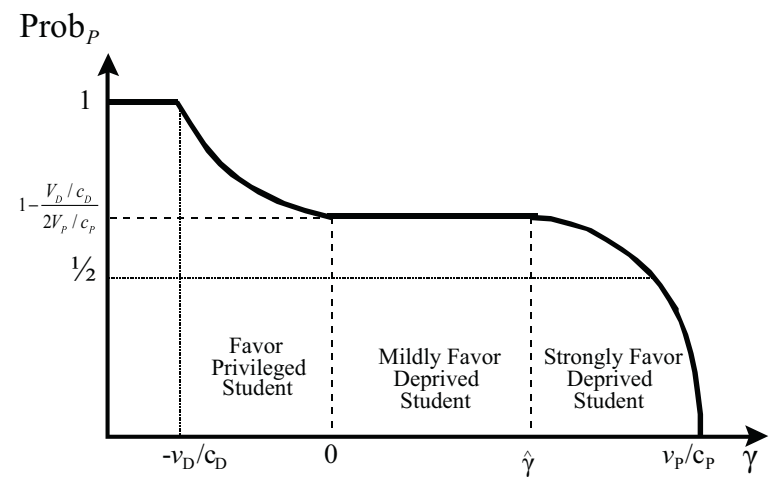

Fig. 2. Admissions probability of the applicant from the privileged background.

of two types of students in the applicant pool. ${ }^{15}$ Hence in this model full diversification occurs with a fifty percent acceptance probability for each applicant.

One might presume that the mild affirmative action implemented to maximize the academic quality of the incoming class would also increase student-body diversity. However in equilibrium, with mild additive preferential treatment the student from the deprived background is not more likely to gain admissions than with a backgroundblind admissions policy. Below we derive the probability that the privileged candidate is admitted, Prob ${ }_{P}$. Fig. 2 graphs $\operatorname{Prob}_{P}$ as a function of $\gamma$.

If the admissions rule implements mild preferential treatment $\gamma \in\left[0, V_{P} / c_{p}-V_{D} / c_{D}\right], u=P$ and $f=D$, then the probability that the privileged candidate is admitted is given by:

$\operatorname{Prob}_{P}=\int_{|\gamma|^{+}}^{|\gamma|+V_{D} / c_{D}} f_{P}(x) F_{D}(x-|\gamma|) d x=1-\frac{V_{D} / c_{D}}{2 V_{P} / c_{P}}>\frac{1}{2}$

Note that in this range of $\gamma$, the probability of admission does not depend on $\gamma$ since the greater effort of the applicant from the privileged background simply offsets the preferential treatment. Mild preferential treatment has no effect on the diversity of the student body. Both a group-blind admissions policy $\gamma=0$ and the equilibrium preferential treatment admissions policy, $\hat{\gamma}=V_{P} / c_{P}-V_{D} / c_{D}$ result in the same percentage of privileged students being admitted which is higher than their representation in the applicant pool. ${ }^{16}$

\footnotetext{
${ }^{15}$ For instance, Trinity College in Dublin admits a percentage of students from the Republic of Ireland and from Northern Ireland equal to the percentage of applicants from each group. We leave it to the reader to determine which group is from the deprived background. In India, higher educational state institutions reserve seats for members of scheduled caste and scheduled tribes. The percentages of reserved seats are determined by the approximate proportions of these groups in the state population (see Weisskopf, 2004). These systems aim at achieving full diversification through setting quotas rather than implementing preferential treatment through a bonus point system. See Hickman (2010) for a discussion of the differences between the two systems.

16 Following the ban on the use of affirmative action in public colleges in California and Texas, Card and Krueger (2005) document that the minority share of freshmen in Berkeley fell from 22\% in 1997 to $12 \%$ in 1998
} 
Proposition 2. At the level of preferential treatment that maximizes the academic quality of the incoming class $\hat{\gamma}$, students from the privileged background are over represented in the incoming class relative to the applicant pool, $\operatorname{Prob}_{P}>1 / 2$. Even though students from the deprived background are subject to favorable preferential treatment of $\hat{\gamma}>0$ their probability of acceptance is the same as under a backgroundblind admissions rule, $\gamma=0$.

With a multiplicative affirmative action rule Fu (2006) finds that the academic quality maximizing choice of admissions policy yields full student-body diversification as a byproduct. Hence there is no tension between academic quality and diversity. This is not the case with an additive preferential treatment policy. The student body is fully diversified only if the college implements strong preferential treatment in favor of the student from the deprived background.

If the admissions policy strongly favors the applicant from the deprived background, $\gamma \in\left(V_{P} / c_{P}-V_{D} / c_{D}, V_{P} / c_{P}\right)$ then the probability that the unfavored applicant, $u=P$, is admitted given by:

$$
\begin{aligned}
\operatorname{Prob}_{P} & =\int_{|\gamma|^{+}}^{V_{P} / c_{P}} F_{D}(x-|\gamma|) f_{P}(x) d x \\
& =\int_{|\gamma|^{+}}^{V_{P} / c_{P}}\left(\frac{c_{P} x}{V_{P}}\right) \frac{c_{D}}{V_{D}} d x=\frac{c_{P} c_{D}}{2 V_{P} V_{D}}\left[\left(\frac{V_{P}}{c_{P}}\right)^{2}-|\gamma|^{2}\right]
\end{aligned}
$$

Note that in this range of $\gamma$ the probability that the candidate from the privileged background is admitted decreases with $|\gamma| \cdot{ }^{17}$ From Eq. (11), the student body is fully diversified, i.e. Prob $_{P}=1 / 2$, when the college implements strong preferential treatment $\tilde{\gamma}=\left[\left(V_{P} / c_{P}\right)\left(V_{P} / c_{P}-V_{D} / c_{D}\right)\right]^{1 / 2}$ in favor of the candidate from the deprived background.

Proposition 3. The level of preferential treatment that yields full student-body diversity is given by $\tilde{\gamma}=\left[\left(V_{P} / c_{P}\right)\left(V_{P} / c_{P}-V_{D} / c_{D}\right)\right]^{1 / 2}$. This level of preferential treatment is strictly higher than the level of preferential treatment that maximizes the academic quality of the incoming class, $\tilde{\gamma}>\hat{\gamma}>0$.

and at Texas A\&M with the introduction of mandated color-blind admissions the minority share of entering freshmen fell from $20 \%$ in 1995 to $12 \%$ in 1997. If previously these institutions were maximizing the academic quality of the incoming class via preferential treatment admissions policies, the model would have predicted no change in the minority share of the incoming class when the admissions policy was forced to be colorblind. Hence the model implies that these institutions were implementing strong preferential treatment implicitly targeting diversity.

17 If the college favors the student from the privileged background $\gamma \in\left(-V_{D} / c_{D}, 0\right)$, the probability that the deprived candidate is admitted is given by:

$$
\begin{aligned}
\operatorname{Prob}_{D}= & \int_{|\gamma|^{+}}^{V_{D} / c_{D}} F_{P}(x-|\gamma|) f_{D}(x) d x \\
& =\int_{|\gamma|^{+}}^{V_{D} / c_{D}}\left(\frac{c_{D} x}{V_{D}}\right) \frac{c_{P}}{V_{P}} d x=\frac{c_{D} C_{P}}{2 V_{D} V_{P}}\left[\left(\frac{V_{D}}{c_{D}}\right)^{2}-|\gamma|^{2}\right]
\end{aligned}
$$

which is identical to Eq. (11) except subscripts $P$ and $D$ exchanged since

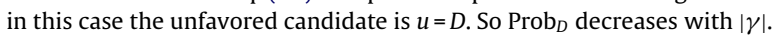

Hence with additive preferential treatment admissions policy, there is a trade off between academic excellence and student-body diversity.

In addition to student-body diversity, the intergroup score gap is frequently considered a key metric of the effect of admissions policies. If the admitted students are more polarized in quality based on their group affiliation, we are more likely to observe statistical discrimination in the postcollege job market. Justice Thomas argues that such Phelps (1972) style discrimination is likely to be exacerbated by affirmative action in the admissions process. "[E]ither racial discrimination did play a role, in which case the person may be deemed 'otherwise unqualified,' or it did not, in which case asking the question itself unfairly marks those blacks who would succeed without discrimination". ${ }^{18}$

Now consider the effect of the optimal admissions rule on the score gap of the admitted students compared to the case with no preferential treatment.

If $\gamma \in\left[0, V_{P} / c_{P}-V_{D} / c_{D}\right]$, then $f=D$ and the expected achievement of an admitted student from a deprived background $\left(Q_{D}\right)$ is given by:

$$
\begin{aligned}
Q_{D} & =\frac{1}{1-\operatorname{Prob}_{P}} \int_{D} x f_{D}(x) F_{P}(x+|\gamma|) d x \\
& =\frac{1}{1-\operatorname{Prob}_{P}} \int_{0}^{V_{D} / c_{D}} \frac{c_{P} c_{D}}{V_{P} V_{D}} x^{2} d x
\end{aligned}
$$

Since $\operatorname{Prob}_{P}$ is given by (10) and does not depend on $\gamma, Q_{D}$ does not depend on $\gamma$.

The expected achievement of an admitted student from the privileged background $\left(Q_{P}\right)$ is given by:

$$
\begin{aligned}
Q_{P}= & \frac{1}{\operatorname{Prob}_{P}} \int_{P} x f_{P}(x) F_{D}(x-|\gamma|) d x=\frac{1}{\operatorname{Prob}_{P}} \int_{|\gamma|^{+}}^{|\gamma|+V_{D} / c_{D}} \\
& \times x \frac{c_{D}}{V_{D}}\left[\frac{V_{P}-\left(c_{P} / c_{D}\right) V_{D}-c_{P}|\gamma|+c_{P} x}{V_{P}}\right] d x
\end{aligned}
$$

Since $\operatorname{Prob}_{P}$ does not depend on $\gamma$, Leibniz's rule yields:

$$
\begin{aligned}
\frac{\partial Q_{P}}{\partial|\gamma|}= & \frac{c_{P} c_{D}}{2 V_{P} V_{D} \operatorname{Prob}_{P}} \\
& \times\left[2\left(\frac{V_{P}}{c_{P}}-\frac{V_{D}}{c_{D}}-|\gamma|\right) \frac{V_{D}}{c_{D}}+\left(\frac{V_{D}}{c_{D}}+|\gamma|\right)^{2}-|\gamma|^{2}\right]
\end{aligned}
$$

Substituting in $\operatorname{Prob}_{P}$ from (10), $\partial Q_{P} / \partial|\gamma|=1$. Hence the score gap $\left(Q_{P}-Q_{D}\right)$ is higher at $\hat{\gamma}$ compared with the gap at $\gamma=0$.

Proposition 4. Compared with a background-blind admissions policy where $\gamma=0$, the score gap is wider with the preferential treatment admissions rule $\hat{\gamma}$ where the academic quality of the incoming class is maximized.

While an academic-quality oriented college implements affirmative action in admissions, this policy does not alter student-body diversity and has the byproduct of increasing the intergroup score gap.

\footnotetext{
18 Grutter v. Bollinger (02-241) 539 U.S. 306 (2003).
} 


\section{Conclusion}

Student-body diversity is commonly cited as the motivation for affirmative action in college admissions. However the college may choose to implement affirmative action even if it is purely academic-quality oriented. The optimal academic excellence admissions policy gives preferential treatment in favor of students from a deprived socioeconomic background in order to maximize competition between potential applicants.

Fu (2006) analyzes multiplicative affirmative action where the academic achievement score of the applicant from a deprived background is multiplied by a scalar greater than 1 . With multiplicative preferential treatment a college maximizing academic quality achieves full studentbody diversity as a byproduct because a multiplicative affirmative action policy creates an additional incentive for students from a deprived background to put in effort.

However often affirmative action admissions policies take, or are perceived to take, an additive form where the college augments the test score of the student from a deprived socioeconomic background by a fixed number of points. We show that the exact form of affirmative action policy matters for student incentives and student-body diversity in equilibrium.

With an additive form of preferential treatment admissions policy, the level of preferential treatment that maximizes the academic quality of the incoming class does not produce full student-body diversity. In fact it does not yield any improvement in student-body diversity compared with a background-blind admissions policy. It fails to incentivize students from deprived backgrounds since the bonus is added to their score irrespective of their effort. But it induces students from privileged backgrounds to put in more effort to overcome the preferential treatment. In equilibrium, the affirmative action has no effect on the representation of deprived students in the incoming class. Furthermore it results in a higher score gap between admitted students from different groups, which may exacerbate statistical discrimination in the post-college job market.

\section{Appendix A. Supplementary data}

Supplementary data associated with this article can be found, in the online version, at doi:10.1016/ j.econedurev.2011.09.005.

\section{References}

Andrews, R. J., Ranchhod, V. \& Sathy, V. (2010). Estimating the responsiveness of college applications to the likelihood of acceptance and financial assistance: Evidence from Texas. Economics of Education Review, 29, 104-115.
Austen-Smith, D. \& Fryer, R. G., Jr. (2005). An economic analysis of 'acting white'. Quarterly Journal of Economics, 120(2), 551-583.

Baye, M., Kovenock, D. \& de Vries, C. (1996). The all-pay auction with complete information. Economic Theory, 8, 291-305.

Bowen, W. \& Bok, D. (1998). The shape of the river: Long-term consequences of considering race in college and university admissions. Princeton, NJ: Princeton University Press.

Card, D. \& Krueger, A. B. (2005). Would the elimination of affirmative action affect highly qualified minority applicants? Evidence from California and Texas. Industrial and Labor Relations Review, 58(3), 416-434.

Chan, J. \& Eyster, E. (2003). Does banning affirmative action lower college student quality? The American Economic Review, 93(3), 858-872.

Che, Y.-K. \& Gale, I. (2003). Optimal design of research contests. American Economic Review, 93(3), 646-671.

Cortes, E. K. (2010). Do bans on affirmative action hurt minority students? Evidence from the Texas top 10\% plan. Economics of Education Review, $29,1110-1124$.

Dickson, L. M. (2006). Does ending affirmative action in college admissions lower the percent of minority students applying to college? Economics of Education Review, 25, 109-119.

Epple, D., Romano, R. \& Sieg, H. (2008). Diversity and affirmative action in higher education. Journal of Public Economic Theory, 10(4), 475-501.

Espenshade, T., Chung, C. \& Walling, J. (2004). Admission preferences for minority students athletes, and legacies at elite universities. Social Science Quarterly, 85(5), 1422-1446.

Fain, J. R. (2009). Affirmative action can increase effort. Journal of Labor Research, 30, 168-175.

Franke, J. (2010). Does affirmative action reduce effort incentives? A contest game analysis. Ruhr Economic Papers, 185.

Fryer, R. G., Jr. \& Loury, G. C. (2005a). Affirmative action and its mythology. Journal of Economic Perspectives, 19(3), 147-162.

Fryer, R. G., Jr. \& Loury, G. C. (2005b). Affirmative action in winner-take-all markets. Journal of Economic Inequality, 3, 263-280.

Fryer, R. G., Jr., Loury, G. C. \& Yuret, T. (2007). An economic analysis of color-blind affirmative action. The Journal of Law, Economics and Organization, 24(2), 319-355.

$\mathrm{Fu}, \mathrm{Q}$. (2006). A theory of affirmative action in college admissions. Economic Inquiry, 44, 420-428.

Furstenberg, E. (2007). The informational value of affirmative action in college admissions. The B.E, Journal of Economic Analysis \& Policy, 7, 1.

Furstenberg, E. (2010). College admissions reform and racial SAT score gaps: An empirical analysis (Working Paper). Department of Economics University of Virginia

Hickman, B. R. (2010). Effort race gaps and affirmative action: A gametheoretic analysis of college admissions (Working Paper). Department of Economics University of Chicago.

Hillman, A. L. \& Riley, J. G. (1989). Politically contestable rents and transfers. Economics and Politics, 1(1), 17-39.

Kane, T. J. (1998). Racial and ethnic preferences in college admissions. In C. Jencks, \& M. Phillips (Eds.), The Black-White test score gap. Washington, DC: Brookings Institution Press.

Konrad, K. A. (2002). Investment in the absence of property rights; the role of incumbency advantages. European Economic Review, 46, 1521-1537.

Li, D. \& Weisman, D. (2011). Why preferences in college admissions may yield a more-able student body. Economics of Education Review, 30(August (4)), 724-728.

Long, M. C. (2004). College applications and the effect of affirmative action. Journal of Econometrics, 121, 319-342.

Phelps, E. S. (1972). The statistical theory of racism and sexism. American Economic Review, 62, 659-661.

Rotthoff, K. W. (2008). Could affirmative action be efficient in higher education? Economics Letters, 99, 574-576.

Weinberger, C. J. \& Joy, L. (2007). The relative earnings of black college graduates 1980-2001. In M. Kim (Ed.), Race, work and economic opportunity in the 21st century. London: Routledge.

Weisskopf, T. E. (2004). Impact of reservation on admissions to higher education in India. Economic and Political Weekly, 39(39), 4339-4349. 